В.А. ГОЛОВАЧЕВА, К.М.Н., В.А. ПАРФЕНОВ, Д.М.Н., профессор

Первый Московский государственный медицинский университет им. И.М. Сеченова Минздрава России (Сеченовский университет)

\title{
TPEВОЖНЫЕ РАССТРОЙСТВА
}

\section{ПОД МАСКОЙ ВЕГЕТОСОСУДИСТОЙ ДИСТОНИИ}

В отечественной медицинской практике широко используется термин «Вегетативно-сосудистая дистония» (ВСД). Однако ВСД не входит в Международную классификацию болезней 10-го пересмотра и не имеет общепринятых диагностических критериев. Данный диагноз обычно устанавливается пациентам молодого и зрелого возраста, не имеющим четкой органической патологии и предъявляющим различные соматические жалобы: на головокружение, головную боль, нарушение сна, сердцебиения, одышку и т. д.

Под маской ВСД часто обнаруживаются тревожные расстройства. В статье рассматриваются современные принципы диагностики и лечения тревожных расстройств. К нелекарственной терапии относятся образовательные беседы, психотерапевтические и психологические методы. Фармакотерапия тревожных расстройств - назначение антидепрессантов, в части случаев в сочетании с транквилизаторами. Если антидепрессанты противопоказаны, при их приеме возникают побочные эффекты или пациент отказывается от их назначения, можно использовать препарат Тенотен. Представлены данные клинических исследований, подтверждающих эффективность и безопасность Тенотена в лечении тревожных расстройств.

Ключевые слова: вегетососудистая дистония, тревога, тревожное расстройство, панические атаки, диагностика, лечение, психотерапия, психологические методы, Тенотен.

V.A. GOLOVACHEVA, PhD in medicine, V.A. PARFENOV, MD, Prof. I.M.Sechenov First Moscow State Medical University, of the Ministry of Health of Russia (Sechenov university) ANXIETY DISORDERS UNDER THE GUIESE OF VEGETOVASCULAR DYSTONIA

The term "vegetovascular dystonia" (VSD) is commonly used in the domestic medical practice. However, the VSD is neither included in the International Classification of Diseases, 10th Edition, nor has any generally accepted diagnostic criteria. This disorder is usually diagnosed in young and mature patients, who do not have any clear organic pathology and present various somatic complaints such as dizziness, headache, sleep disturbances, palpitations, shortbreathing, etc.

But under the guise of the VSD, physicians often discover anxiety disorders. The article deals with the advanced principles of diagnosis and treatment of the anxiety disorders. Non-drug therapy includes educational conversations, psychotherapeutic and psychological methods. Pharmacotherapy of anxiety disorders comprises the administration of antidepressants, in some cases combined with tranquilizers. If antidepressants are contraindicated, but used, side effects may occur, or if the patient refuses to take them, Tenoten may be prescribed. The article presents clinical studies data confirming the efficacy and safety of Tenoten in the treatment of anxiety disorders.

Keywords: vegetovascular distonia, anxiety, anxiety disorder, panic attacks, diagnosis, treatment, psychotherapy, psychological methods, Tenoten.

егетососудистая дистония (ВСД) - диагноз, который часто ставят пациентам молодого и зрелого возраста в терапевтической и неврологической практике в России [1, 2]. Данная патология не внесена в настоящую Международную классификацию болезней 10-го пересмотра (МКБ-10) и не будет входить в новую Международную классификацию болезней 11-го пересмотра (МКБ-11). Термин «ВСД» не применяется в мировой медицине и используется только в России, странах ближнего зарубежья. Ошибочный диагноз «ВСД» ставится пациентам, которые реально страдают другими заболеваниями. Постановка ошибочного диагноза «ВСД» приводит к назначению неэффективного лечения, формированию у пациентов неправильных представлений о своем состоянии и во многих случаях - к ухудшению настоящего заболевания.

В практической деятельности ошибочный диагноз «ВСД» обычно часто ставится пациентам, которые не имеют структурных повреждений нервной и сердечнососудистой системы и предъявляют различные жалобы на головную боль, нарушение сна, ощущение «тяжести» в голове, снижение памяти, головокружение, повышенную утомляемость, сниженное настроение, тревогу, ощущения сердцебиения и нехватки воздуха [3-5]. Под маской ВСД могут обнаруживаться неврологические расстройства (первичные головные боли, вестибулопатии, инсомния, нейрогенные обмороки), психические нарушения (тревожные расстройства, депрессия, соматоформное расстройство) и ряд соматических заболеваний (нарушения ритма сердца, ишемическая болезнь сердца, заболевания щитовидной железы и др.) [4-7].

\section{ТРЕВОЖНЫЕ РАССТРОЙСТВА ПОД МАСКОЙ ВСД}

Тревожные расстройства - одни из самых распространенных состояний, которые ошибочно расцениваются как ВСД. Пациенты с тревожными расстройствами обычно предъявляют различные соматические жалобы, поэтому могут встречаться в практической деятельности врачей многих специальностей. Большинство пациентов с тревожными расстройствами проходят дополнительные исследования, на основании которых часто устанавливаются оши- 
бочные причинно-следственные связи между результатами исследований и клиническими симптомами. Например, клинически незначимая асимметрия кровотока по позвоночным артериям расценивается как причина эпизодов несистемного головокружения, ощущения нехватки воздуха и «тяжести» в голове. Неправильная интерпретация результатов исследования способствует катастрофизации соматических симптомов, беспокоящих пациента, и усилению тревоги. Также в практической деятельности распространены случаи сочетания неврологического и/или соматического заболевания с тревожным расстройством [1, 2, 5-7]. В данных клинических ситуациях рекомендуется междисциплинарный подход: совместное ведение пациента неврологом, психиатром и/или терапевтом.

Распространено сочетание хронической ежедневной головной боли (ХЕГБ) и тревожных расстройств - в этой группе от 42 до 72\% пациентов имеют ошибочный диагноз «ВСД» $[6,7]$. По результатам собственного наблюдения 90 пациентов с ХЕГБ (хронической мигренью, хронической головной болью напряжения в сочетании или без эпизодической мигрени) у $40 \%$ ранее был поставлен ошибочный диагноз «ВСД» $[5,6]$. В группе пациентов с ХЕГБ, которым ставился диагноз «ВСД», более чем у половины (52\%) были диагностированы эмоциональные нарушения в виде тревожного и тревожно-депрессивного расстройства. Предшествующая практика ведения пациентов с головной болью под маской ВСД заключалась в назначении дополнительных методов исследований (электроэнцефалография, реоэнцефалография, ультразвуковое исследование сосудов шеи, магнитно-резонансная ангиография головного мозга) при отсутствии обоснованных показаний к их проведению, а также использовании нейрометаболических препаратов, анксиолитиков, не улучшающих состояние пациентов. Повторные посещения медицинских учреждений, ожидания результатов исследований, нередкая ошибочная интерпретация клинически незначимых изменений по данным инструментальных исследований как причин заболевания пациента, негативный опыт лечения - все это приводило к катастрофизации симптомов пациентом [8]. Известно, что катастрофизация боли и дискомфортных ощущений значимый фактор в поддержании и прогрессировании болевого синдрома, эмоциональных расстройств и их соматизации $[8,9]$. Сочетанное применение когнитивноповеденческой терапии [10] и стандартной фармакотерапии мигрени, головной боли напряжения (антидепрессантов, антиконвульсантов или бета-адреноблокаторов) [11, 12] позволило быстро достигнуть устойчивого терапевтического эффекта у большинства $(72,2 \%)$ пациентов.

\section{ДИАГНОСТИКА ТРЕВОЖНЫХ РАССТРОЙСТВ}

В соответствии с МКБ-10 к группе тревожных расстройств относятся паническое расстройство, генерализованное тревожное расстройство, смешанное тревожное и депрессивное расстройство, фобическое тревожное расстройство (агорафобия, социальные фобии, специфические фобии) [13].
Наиболее часто в практической деятельности невролога встречается паническое расстройство и генерализованное тревожное расстройство $[14,15]$.

Тревожное расстройство диагностируется на основании данных анамнеза и специальных опросников в соответствии с диагностическими критериями МКБ-10; необходимо исключение вторичных причин тревоги $[15,16]$.

В практической медицине для выявления симптомов тревоги целесообразно использовать специальные опросники: шкалу ситуативной и личностной тревожности Спилбергера - Ханина, госпитальную шкалу тревоги и депрессии, шкалу тревоги Гамильтона $[15,17]$.

Дифференциальный диагноз тревожного расстройства следует проводить с рядом заболеваний и состояний, которые клинически могут также проявляться психовегетативными симптомами: эндокринные заболевания (заболевания щитовидной железы, феохромоцитома, предменструальное дисфорическое расстройство), соматические заболевания (нарушения ритма сердца, артериальная гипертензия, ишемическая болезнь сердца, бронхиальная астма, хроническая обструктивная болезнь легких), неврологические заболевания (эпилепсия, синдром постуральной тахикардии), действие определенных веществ (амфетамина, кофеина, алкоголя, барбитуратов, бензодиазепинов) и другие психические расстройства (фобии, посттравматическое стрессовое расстройство, обсессивно-компульсивное расстройство и т. д.) [18]. Однако вышеперечисленные заболевания могут и сосуществовать с тревожным расстройством.

Паническое расстройство - заболевание, которое проявляется возникновением панических атак с различной частотой и их тревожным ожиданием в межприступном периоде [19]. Паническое расстройство может протекать с агорафобией (в большинстве случаев) или без нее. Агорафобия - боязнь открытого пространства, страх скопления людей, часто испытываемый при прохождении без провожатых по большой площади или безлюдной улице. Диагноз панического расстройства устанавливается на основании критериев МКБ-10 (табл. 1) [13].

Панические атаки - приступы внезапно возникающей тревоги, которые проявляются рядом физических ощущений и страхом потери контроля над своим состоянием, страхом потери сознания, сойти с ума или страхом смерти (табл. 2) [19].

\section{Таблица 1. Диагностические критерии панического расстройства по МКБ-10}

1. Повторное возникновение панических атак. Для диагностики панического расстройства необходимы как минимум две спонтанные панические атаки в течение месяца. У пациентов с паническим расстройством могут возникать ситуативно-обусловленные панические атаки

2. Панические атаки наблюдаются в течение месяца и более и сопровождаются следующими симптомами:

- постоянным беспокойством по поводу повторения атак,

- беспокойством по поводу осложнений атак или их последствий (потеря контроля над собой, тяжелая органическая патология),

- значимыми изменениями поведения из-за возникновения атак

Возникновение атак не обусловлено соматическими заболеваниями, действием каких-либо веществ и другими психическими заболеваниями 


\section{Таблица 2. Признаки и симптомы панической атаки}

1. Страх потери контроля над собой, страх потери сознания, сойти с ума или страх смерти

2. Со стороны сердечно-сосудистой системы: тахикардия, ощущение сердцебиения, «перебоев» в работе сердца, кардиалгии, неприятные ощущения в грудной области, повышение или понижение артериального давления, дистальный акроцианоз, ощущение жара или холода

3. Со стороны дыхательной системы: ощущение нехватки воздуха, одышка, затрудненное дыхание, ощущение «кома» в горле, непродуктивный кашель

4. Со стороны желудочно-кишечного тракта: сухость во рту, тошнота, рвота, отрыжка, боли в животе, метеоризм, запоры или поносы

5. Со стороны систем терморегуляции и потоотделения: неинфекционное субфебрильное повышение температуры, ощущение «озноба», диффузный или локальный гипергидроз

6. Со стороны нервной системы: несистемное головокружение, ощущение неустойчивости, предобморочное состояние, тремор, парестезии

7. Со стороны мышечной системы: повышение тонуса скелетных мышц, ощущение «напряжения» в теле, миалгия, мышечные подергивания, тремор

Достоверный критерий панической атаки - наличие тревоги и 4 вышеперечисленных физических ощущений $[18,19]$. Выраженность панической атаки может варьировать в широких пределах: от ощущения внутреннего напряжения до сильного страха смерти. У одного и того же пациента, наряду с «развернутыми» паническими атаками, могут возникать «малые» панические атаки, которые проявляются 2-3 симптомами. Наблюдаются так называемые панические атаки без страха или «паника без паники», при которых преобладают физические ощущения, а эмоциональный компонент проявляется лишь небольшим ощущением «внутреннего напряжения». Продолжительность панической атаки обычно составляет 15-30 минут. Панические атаки могут возникать в дневное (чаще всего) и ночное время суток. Большинство пациентов указывают на спонтанность их возникновения, однако при более подробном расспросе могут выявляться и ситуативно-обусловленные панические атаки, возникающие в определенных ситуациях или обстоятельствах: общественном транспорте, закрытых или душных помещениях и т.п. Паническая атака может провоцироваться приемом алкоголя, курением, недостатком сна, менструацией.

Генерализованное тревожное расстройство - заболевание, которое характеризуется наличием ежедневной или практически ежедневной тревоги и связанных с ней соматических и когнитивных симптомов на протяжении 6 и более месяцев [20]. Генерализованное тревожное расстройство - это хроническое состояние тревоги, при котором отсутствуют бессимптомные, «светлые» промежутки, характерные для панического расстройства. Пациент с генерализованным тревожным расстройством с трудом может контролировать ощущение беспокойства [19]. Характерны двигательное беспокойство, мучительное состояние неопределенности, утомляемость, снижение памяти, трудности концентрации внимания, раздра- жительность, мышечное напряжение, нарушение сна (трудности засыпания, ранние пробуждения и/или ночные пробуждения). Тревога и перечисленные соматические, когнитивные симптомы значимо влияют на качество жизни, снижают социальную и профессиональную активность, зачастую приводя к нетрудоспособности пациента.

Диагноз генерализованного тревожного расстройства ставится на основании критериев МКБ-10 [13]:

1) распространенная и устойчивая тревога, которую не ограничивают и не вызывают какие-либо особые обстоятельства;

2) доминирующие симптомы изменчивы, но часто включают жалобы на устойчивую нервозность, ощущение страха, мышечное напряжение, потливость, дрожь, головокружение и чувство дискомфорта в эпигастральной области;

3) выражена боязнь несчастного случая или болезни, которые, по мнению больного, ожидают его или его родственников в ближайшее время.

\section{ЛЕЧЕНИЕ ТРЕВОЖНЫХ РАССТРОЙСТВ}

Тревожные расстройства относятся к кругу психических заболеваний и требуют активного участия психиатра. Но в ряде случаев пациенты могут отказаться от обращения к психиатру по каким-либо личным соображениям. Поэтому таких пациентов ведет невролог или врач другой специальности; кроме этого, у пациентов с тревожными расстройствами часто имеются другие неврологические заболевания (первичные головные боли, головокружения, инсомния и др.), требующие лечение у невролога [21].

План лечения пациента составляется на основании формы и выраженности тревожного расстройства, сочетанных заболеваний, индивидуальных противопоказаний, предшествующего опыта лечения, предпочтений пациента. Выделяют лекарственные и нелекарственные методы лечения тревожного расстройства. Оптимально назначение комплексной терапии тревожного расстройства в соответствии с положениями международных рекомендаций $[16,19]$.

В лечении панического расстройства, генерализованного тревожного расстройства, фобических тревожных расстройств эффективны фармакотерапия и психотерапия [16]. Первый этап лечения тревожных расстройств образовательная беседа с пациентом по поводу его заболевания. Рекомендуется разъяснить причины и прогноз заболевания, рассказать о современных методах лечения тревожного расстройства. Важно проинформировать пациента о существующих методах психотерапии тревожных расстройств и учитывать его предпочтения в выборе определенного метода психотерапии. Также следует проинформировать больного о лекарственных средствах, эффективных в лечении тревожного расстройства, о сроках наступления терапевтического эффекта, возможных побочных эффектах, противопоказаниях, возможных ограничениях в образе жизни во время приема препаратов. 
Среди существующих методов психотерапии когнитивно-поведенческая терапия обладает самой высокой эффективностью в лечении панического расстройства, генерализованного тревожного расстройства, агорафобии, социальных фобий, специфических фобий [16]. Психодинамическая психотерапия - психотерапия второго выбора и может быть предложена в тех случаях, когда проведение когнитивноповеденческой терапии невозможно, сессии когнитивноповеденческой терапии оказались неэффективны или пациент предпочел психодинамическую психотерапию.

В лечении тревожных расстройств и симптомов тревоги доказана эффективность такого психологического метода лечения, как «майндфулнесс» (практики осознанности или просветления) [22]. Метод «майндфулнесс» заключается в выполнении медитационных упражнений, без религиозной составляющей, в удобных физиологических позах. Основная идея терапевтической техники «майндфулнесс» - полное перенесение внимания на настоящий момент, без какой-либо оценки себя и окружающей действительности [23]. С помощью «майндфулнесс» пациент обучается тому, как быть «здесь и сейчас», как останавливать навязчивые, беспокоящие мысли, контролировать эмоции, повысить эмоциональную устойчивость к стрессу и получать удовольствие от жизни.

В качестве дополнительной или альтернативной терапии панического расстройства может быть предложена лечебная гимнастика, бег, пешие прогулки, дыхательные упражнения [16].

В лечении тревожных расстройств к лекарственным средствам первого выбора относятся антидепрессанты из группы селективных ингибиторов обратного захвата серотонина, а также из группы ингибиторов обратного захвата серотонина и норадреналина [16]. Для снижения риска рецидива тревожных расстройств рекомендуется прием фармакотерапии в течение 6-12 месяцев после клинической ремиссии. В лечении панического расстройства с агорафобией и без нее к препаратам первого выбора относятся циталопрам (20-40 мг в день), эсциталопрам (10-20 мг в день), пароксетин (20-50 мг в день), сертралин (50-150 мг в день), венлафаксин (75-225 мг в день). В лечении панического расстройства с агорафобией и без нее в качестве препарата второго выбора рекомендуется трициклический антидепрессант кломипрамин (75-250 мг в день). При генерализованном тревожном расстройстве к препаратам первого выбора относятся эсциталопрам (10-20 мг в день), пароксетин (20-50 мг в день), венлафаксин (75-225 мг в день), дулоксетин (60120 мг в день); к препарату второго выбора относится антиконвульсант прегабалин (150-600 мг в день). В лечении социальных фобий эффективны эсциталопрам (1020 мг в день), пароксетин (20-50 мг в день), сертралин (50-150 мг в день), венлафаксин (75-225 мг в день).

При наличии противопоказаний к назначению антидепрессантов, возникновении побочных эффектов на фоне их терапии или нежелании пациента принимать антидепрессанты возможно назначение препаратов с анксиолитической и антидепрессивной активностью других фармакологических групп. В практической деятельности распространено назначение препаратов бензодиазепинового ряда пациентам с тревожным и тревожно-депрессивным расстройствами. Однако терапия бензодиазепинами имеет ряд недостатков. Прием бензодиазепинов сопряжен с развитием лекарственной зависимости, ухудшением когнитивных функций и координации движений и такими побочными эффектами, как дневная сонливость, ощущение общей слабости, двигательная заторможенность, замедленность мышления, речи [24-26]. В связи с этим были разработаны препараты, обладающие противотревожной активностью, сопоставимой с бензодиазепинами, но не вызывающие характерных для них побочных эффектов и зависимости. К таким препаратам относится Тенотен.

Тенотен - препарат с успокаивающим, противотревожным (анксиолитическим) действием, не вызывает нежелательных гипногенного и миорелаксантных эффектов [25]. Также обладает вегетотропным действием [25]. Улучшает переносимость психоэмоциональных нагрузок. Тенотен содержит релиз-активные формы антител к мозгоспецифическому белку S100 (P-A AT S100) [26]. Данный белок относится к группе $\mathrm{Ca}^{2+}$-связывающих белков, является важным модулятором нейрональных процессов, лежащих в основе механизмов синаптической пластичности [27]. Анксиолитический эффект Тенотена связан с его взаимодействием с ГАМК-А-бензодиазепиновым рецепторным комплексом, ГАМК-миметическим действием [27]. Тенотен приводит к восстановлению процессов возбуждения и торможения в центральной нервной системе [25].

Анксиолитическое и вегетотропное действия Тенотена, его хорошая переносимость и безопасность в лечении пациентов с тревожными расстройствами подтверждены результатами ряда клинических исследований.

В открытом простом сравнительном многоцентровом исследовании 80 пациентов с генерализованным тревожным расстройством, неврастенией, расстройством адаптации или смешанным тревожно-депрессивным расстройством получали терапию Тенотеном или диазепамом (15 мг в день) в течение 28 дней. Было показано, что по анксиолитическому действию Тенотен незначительно (не достигая пределов статистической значимости) уступает диазепаму. Главное преимущество терапии Тенотеном перед терапией диазепамом - высокий показатель безопасности, отсутствие побочных эффектов, в частности дневной сонливости, миорелаксации и ортостатических нарушений [25].

Имеются данные, что Тенотен сопоставим по противотревожному эффекту с феназепамом, превосходит его по переносимости, отсутствию побочных эффектов, отсутствию синдрома отмены после прекращения приема препарата [28].

Эффективность Тенотена и сопоставимость его анксиолитического эффекта с действием типичного бензодиазепинового анксиолитика тофизопама показаны при сравнении 4-недельной терапии Тенотеном и тофизопамом (по 50 мг 2 раза в день) у пациентов с генерализованным тревожным расстройством, смешанным тревожно-депрессивным расстройством и сочетанными соматическими заболеваниями - артериальной гипертензией (АГ) и ишемической болезнью сердца [29]. В открытом 
сравнительном исследовании было продемонстрировано, что Тенотен по своему анксиолитическому эффекту лишь незначительно уступает клоназепаму в лечении расстройств тревожного спектра (тревожно-депрессивных расстройств, тревожно-ипохондрических реакций) у пожилых пациентов с сочетанными сердечно-сосудистыми заболеваниями, при этом Тенотен не вызывает заторможенности, сонливости и лекарственной зависимости, в отличие от клоназепама [30]. На основании того, что тревога - фактор риска развития АГ, добавление Тенотена к антигипертензивной терапии у пациентов с АГ и высоким уровнем тревоги способствует более эффективному лечению АГ, оказывая анксиолитический и ассоциированный с ним дополнительный гипотензивный эффект [32].

Рекомендуется назначение Тенотена в комплексной терапии тревожного расстройства. Оптимально назначение Тенотена по 1 таблетке 3 раза в день в течение 4 недель [31]. Возможно увеличение продолжительности терапии до 12 недель [31]. При отсутствии эффекта через 4 недели приема препарата рекомендуется подбор другой терапии для коррекции эмоциональных расстройств, консультация психиатра.
В ходе лечения целесообразно периодически проводить повторные оценки эмоционального статуса.

Таким образом, под маской ошибочного диагноза «ВСД» часто обнаруживаются другие заболевания неврологические, психические и/или соматические. Тревожные расстройства в сочетании или без неврологического расстройства - одни из самых распространенных масок ВСД. Диагностика тревожных расстройств основывается на официальных критериях МКБ-10 и исключении вторичного характера психовегетативных симптомов. В лечении тревожных расстройств эффективны психотерапевтические и психологические методы, антидепрессанты. В ряде случаев для лечения тревожного расстройства может применяться препарат Тенотен. Эффективность и безопасность терапии Тенотеном при тревожных расстройствах подтверждена результатами клинических исследований. Наиболее эффективно проведение комплексного лечения, включающего нелекарственные методы и фармакотерапию. Данный подход с высокой вероятностью обеспечит долгосрочность поддержания достигнутого клинического эффекта.

\section{ЛИТЕРАТУРА}

1. Яхно Н.Н., Парфенов В.А., Рейхарт Д.В. и др. Многоцентровая неинтервенционная проспективная наблюдательная программа изучения практики назначения препарата тералиджен у больных с диагнозом вегетативного расстройства (СТАРТ-2: российский опыт применения русскоязычной валидированнной версии опросника 4DSO. Промежуточный анализ). Журнал неврологии и психиатрии имени С.С. Корсакова, 2015, 114(5): 27-33.

2. Яхно Н.Н., Смулевич А.Б., Терлуин Б. и др. Первичный скрининг пациентов, страдающих автономными (вегетативными) расстройствами в условиях повседневной амбулаторной неврологической практики РФ (СТАРТ 1): применение русскоязычной версии четырехмер ного опросника симптомов дистресса, депрессии, тревоги и соматизации 4DSO (The Four Dimensional Symptoms Questionnaire) Журнал неврологии и психиатрии имени С.С. Корсакова, 2014; 114(12): 112-122.

3. Головачева В.А., Андрющенко А.В. Паническое расстройство в неврологической практике Фарматека 2015, 3: 39-43.

4. Головачева В.А., Парфенов В.А., Табеева Г.Р. Осипова В.В., Смулевич А.Б., Андрющенко А.В., Головачева А.А. Оптимизация ведения пациентов с хронической ежедневной головной болью. Журнал неврологии и психиатрии им. С.С. Корсакова, 2017, 117(2): 4-9.

5. Головачева В.А. Оптимизация ведения пациентов с хронической ежедневной головной болью: Дисс. ...канд. мед. наук: М., 2016, 134

6. Азимова Ю.Э., Сергеев А.В., Осипова В.В. Табеева Г.Р.Диагностика и лечение головных болей в России: результаты анкетного опроса врачей. Российский журнал боли, 2010, 3-4: 12-17.

7. Лебедева Е.Р., Кобзева Н.Р., Гилев Д.В., Олесен Е. Анализ качества диагностики и лечения первичной головной боли в разных социальных группах Уральского региона. Неврология, нейропсихиатрия, психосоматика, 2015, 1: 19-26.

8. Myles P., Shafran R. The CBT hadbook. A comprehensive guide to using Cognitive Behavioural Therapy to overcome depression, anxiety and anger. London, Robinson, 2004, 524.
9. Осипова В.В. Психологические аспекты боли. Неврология, нейропсихиатрия, психосоматика 2010, 2(1): 4-8.

10. Otis J.D. Managing chronic pain: a cognitivebehavioral therapy: therapist guide, $1^{\text {st }}$ ed. New York, Oxford University Press, 2007,114.

11. Evers $S, A^{\prime}$ fra J, Frese $A$ et al. EFNS guideline on the drug treatment of migraine - revised report of an EFNS task force. Eur J Neurol, 2009, 16: 968-981.

12. Bendtsen L, Evers S, Linde $M$ et al. EFNS guideline on the treatment of tension-type headache - Report of an EFNS task force. Eur J Neurol, 2010, 17: 1318-1325.

13. World Health Organization. International statistical classification of disease and relation health problems. $10^{\text {th }}$ ed. Geneva, Switz: World Health Organization, 1992

14. Hoffelt C, Zwack A. Assessment and management of chronic pain in patients with depression and anxiety. Mental Health Clinician, 2014, 4(3): 146-152.

15. Woo Adam KM. Depression and Anxiety in Pain Reviews in pain, 2010, 4(1): 8-12.

16. Bandelow B, Lichte T, Rudolf S, Wiltink J, Beutel ME.The diagnosis of and treatment recommendations for anxiety disorders. Dtsch Arztebl Int, 2014, 111(27-28): 473-80.

17. Воробьева О.В. Тревожные расстройства в неврологической практике. РМЖ, 2007, 24

18. Воробьева О.В. Панические атаки. Клиника, диагностика, лечение. М.: «АМА-ПРЕСС», 2009, 46.

19. Клиническое руководство по психическим расстройствам. Под ред. Барлоу Д. 3-е изд. СПб.: Питер, 2008, 912.

20. Shelton $\mathrm{Cl}$. Diagnosis and management of anxiety disorders. J Am Osteopath Assoc, 2004, 104(3, l): 2-5.

21. Головачева В.А., Андрющенко А.В. Паническое расстройство в неврологической практике. Фарматека, 2015, 3: 39-43.

22. Castelnuovo G, Giusti EM, Manzoni GM et al. Psychological treatments and psychotherapies in the neurorehabilitation of pain: evidences and recommendations from the Italian consensus conference on pain in neurorehabilitation. Frontiers in Psychology, 2016, 7: 115.

23. The mindfulness solution to pain: step-by-step techniques for chronic pain management.
Jackie Gardner-Nix with Lucie Costin-Hall, foreword by Jon Kabat-Zinn, USA, New Harbinger Publication, Inc, 2009, 210

24. Troisi E, Paolucci S, Silvestrin $M$ et al. Prognostic factors in stroke rehabilitation: the possible role of pharmacological treatment. Acta. Neurol. Scand., 2002, 105: 100-106.

25. Аведисова А.С., Ястребов Д.В. Отчет о клинических испытаниях эффективности и переносимости препарата «Тенотен» в качестве анксиолитического средства при терапии тревожных состояний. 2004, 15

26. Эпштейе О.И. Релиз-активность (современный взгляд на гомеопатию и негомеопатию). М.: Издательство РАМН, 2017, 48.

27. Шавловская О.А. Применение препарата Тенотен в клинической практике. Эффективная фармакотерапия, 2011, 4: 20-28.

28. Серова Л.Д. Тенотен в комплексной терапии цереброваскулярной недостаточности у пожилых больных. Неврология. Нейропсихиатрия. Психосоматика, 2009, 1: 41-44.

29. Амосов М.Л., Салеев Р.А., Зарубина Е.В. и др. Применение препарата Тенотен при лечении эмоциональных расстройств у пациентов с преходящими нарушениями мозгового кровообращения. Российский психиатрический журнал, 2008, 3: 86-89.

30. Ванчакова Н.П., Попов А.П. Тревожные расстройства у пациентов с гипертонической болезнью и ишемической болезнью сердца и опыт их коррекции Тенотеном. Поликлиника, 2007, 2: 74-78.

31. Ромасенко Л.В., Недоступ А.В., Артюхова М.Г. и др. Применение препарата Тенотен при лечении невротических расстройств у пациентов с заболеваниями сердечно-сосудистой системы. Российский психиатрический журнал, 2007, 2: 81-84

32. Шавловская О.А. Применение препарата Тенотен в клинической практике. Эффективная фармакотерапия, 2011, 4 20-28.

33. Никольская И.Н., Гусева И.А., Близневская Е.В. и др. Роль тревожных расстройств при гипертонической болезни и возможности их коррекции. Лечащий врач, 2007, 3: 89-91. 